\section{Colóquio Nacional sobre o Trabalho do Assistente Social}

\author{
II National Colloquy on the Social \\ Worker's Work
}

Rosa Lúcia Prédes Trindade*

O II Colóquio Nacional sobre o Trabalho do Assistente Social, com o tema Espaços sócio-ocupacionais e tendências do mercado de trabalho do Serviço Social no contexto de reconfiguração das politicas sociais no Brasil, ocorreu nos dias 31 de julho, 1 e 2 de agosto de 2013, na Faculdade de Serviço Social da Universidade Federal de Alagoas (UFAL). O evento foi promovido pelos Programas de Pós-Graduação em Serviço Social da UFAL, UFRJ e PUC-SP no âmbito do Programa Nacional de Cooperação Acadêmica - PROCAD/

* Doutora em Serviço Social pelo Programa de Pós-Graduação em Serviço Social da Universidade Federal do Rio de Janeiro (UFRJ); professora da Faculdade de Serviço Social da Universidade Federal de Alagoas, Maceió/AL, Brasil. Participante da Rede de Pesquisa sobre o trabalho do assistente social (Retas), sendo sua coordenadora no período 2006-2012, e coordenadora do Projeto Integrado de Pesquisa Procad Casadinho (UFAL, UFRJ, PUC-SP). E-mail: rosapredes@uol.com.br.
Casadinho, e organizado pelos Grupos de Pesquisa - Mercado de Trabalho do Serviço Social; Trabalho e Serviço Social (Trasso); Políticas Públicas, Controle Social e Movimentos Sociais - do Programa de Pós-Graduação em Serviço Social da UFAL.

O colóquio teve sua realização prevista no projeto integrado de pesquisa que tem como tema os espaços sócio-ocupacionais do Serviço Social e o mercado de trabalho profissional, analisados no contexto de reestruturação produtiva e de reforma (contrarreforma) do Estado e das políticas sociais no Brasil no século XXI. Trata-se de pesquisa financiada pela Capes/CNPq no âmbito do Edital Procad/Casadinho (2012-2015), realizada pelos grupos de pesquisa da UFAL, anteriormente citado e coordenados pelas pesquisadoras Rosa Prédes, Maria Virgínia Borges Amaral e Valéria Correia; da PUC-SP - Trabalho e Profissão, coordenado por Raquel Raichelis; da UFRJ - Fundamentos do Serviço Social na Contemporaneidade, coordenado por Yolanda Guerra, que se dedicam ao estudo sobre o Serviço Social nas questões relativas aos fundamentos, à formação profissional, ao mercado de trabalho e ao trabalho do assistente social.

Esta articulação entre os grupos de pesquisa e os programas de pós-graduação em Serviço Social é parte dos objetivos e ações da Rede de Pesquisa 
sobre o Trabalho do Assistente Social (Retas), ativa desde o ano de 2006. A proposta inicial de articulação de uma Rede de Pesquisa sobre o trabalho do assistente social decorreu de uma série de conversas e discussões entre os pesquisadores da área do Serviço Social sobre a necessidade de uma maior visibilidade e de mais incentivo aos estudos sobre o trabalho do assistente social na atualidade, especialmente sobre as pesquisas que tratam sobre mercado de trabalho e exercício profissional. Em 2004, o CFESS viabilizou uma pesquisa sobre o perfil profissional do assistente social, em parceria com a UFAL, cujos resultados mostraram a necessidade e a potencialidade para as investigações sobre a profissão. Na Oficina da Abepss em Fortaleza (junho de 2006) iniciou-se um levantamento dos pesquisadores interessados nesse tema, o que foi complementado por contatos via internet nos meses de julho e agosto de 2006 e pela realização de um Colóquio regional (Nordeste) sobre o trabalho do assistente social realizado na UFAL em setembro de 2006 com a participação da UFAL, UFRN, UERN, UFS, UEPB.

No ENPESS de 2006 em Recife, a Retas foi apresentada na Oficina de Redes de Pesquisa, configurando-se um processo histórico que iniciara nos Enpess de 2000, 2002 e 2004 - com a organização de mesas coordenadas com pesquisadores atuantes no tema sobre o trabalho do assistente social - e no colóquio regional Nordeste. Seguiram-se reuniões nacionais da Rede nos eventos nacionais da área de Serviço Social em 2008, 2010 e 2012 e a organização de mesas coordenadas nos Enpess de 2008, 2010 e 2012. Em maio de 2010 a Retas realizou seu primeiro encontro científico: o I Colóquio Nacional sobre o Trabalho do Assistente Social, com o tema Trabalho na sociedade contemporânea e o trabalho do assistente social, organizado pelo Programa de Pós-Graduação em Serviço Social da Faculdade de Serviço Social da UFAL (cf. <http://coloquio-sso.blogspot.com/>). Em 2011, os grupos de pesquisa dos PPGSS da UFAL, UFRJ e PUC-SP elaboraram, no âmbito da Retas, a proposta de pesquisa integrada em desenvolvimento, com apoio Procad/Casadinho. Tanto a Retas quanto a pesquisa Procad fazem parte do esforço coletivo de consolidar o Grupo Temático de Pesquisa da Abepss (GTP) Serviço Social: Fundamentos, Formação e Trabalho Profissional.

Atualmente, a Rede envolve 14 grupos de pesquisa, 12 deles vinculados a programas de pós-graduação da área de Serviço Social (UFAL, UFMA, UFMT, UFJF, UFRJ, PUC-SP, Unesp/Franca, UFSC, UFS, UEPB).

Portanto, a realização do II Colóquio Nacional sobre o Trabalho do Assistente Social, ocorrido em julho e agosto de 2013, consolida esta articulação 
de pesquisas sobre o trabalho do assistente social. Por isso mesmo, seus objetivos foram: promover a divulgação e a discussão dos estudos sobre o trabalho do assistente social; subsidiar o desenvolvimento da pesquisa integrada apoiada pelo Procad/Casadinho; incrementar o mapeamento das pesquisas sobre o trabalho do assistente social; fortalecer a articulação da Rede de Pesquisa sobre o trabalho do assistente social; contribuir para a consolidação do Grupo Temático de Pesquisa da Abepss (GTP) Serviço Social: Fundamentos, Formação e Trabalho Profissional. A forma de Colóquio permitiu que os participantes do encontro não apenas compartilhassem seus trabalhos acadêmicos, mas também discutissem os aspectos controversos da realidade social e as demandas postas para o assistente social, identificados em seus estudos. Para favorecer o debate, os textos com os conteúdos dos trabalhos apresentados foram disponibilizados antecipadamente no blog $<\mathrm{http}$ ://coloquionacionalufal.blogspot.com.br/>.

O Colóquio articulou pesquisadores dedicados aos estudos sobre os espaços sócio-ocupacionais e as tendências do mercado de trabalho do Serviço Social no contexto de reconfiguração das políticas sociais no Brasil. A comissão científica recebeu a inscrição de 57 trabalhos provenientes dos Estados de AL, PE, PB, RN, SE, BA, RJ, MG, SP, SC, $\mathrm{PR}, \mathrm{MT}$, e selecionou 20 que tratavam sobre proposta do colóquio, seguindo-se os critérios condizentes com os objetivos e características do evento: Trabalhos com resultados de pesquisas concluídas, com conteúdos cujo debate pode contribuir para a pesquisa integrada sobre o tema, com autoria de pesquisadores profissionais, podendo contar com participação de alunos de iniciação científica e de pós-graduação stricto sensu. Os trabalhos foram agrupados em temáticas - Reestruturação produtiva, Reforma do Estado e das Políticas Sociais e o trabalho do assistente social; Espaços sócio-ocupacionais do Serviço Social e Mercado de trabalho; Espaços sócio-ocupacionais do Serviço Social e Mercado de trabalho - e apresentados em mesas redondas por pelo menos um dos autores, seguindo-se os debates sobre os conteúdos apresentados, considerando-se os objetivos e o tema geral do colóquio. A mesa de abertura do colóquio: Espaços sócio-ocupacionais e tendências do mercado de trabalho do Serviço Social no contexto de reconfiguração das políticas sociais no Brasil: produção científica dos grupos de pesquisa (Procad) - teve a participação dos grupos de pesquisa dos PPGSS promotores, contando com as exposições de Rosa Prédes (UFAL), Raquel Raichelis (PUC-SP) e Yolanda Guerra (UFRJ).

A realização do Colóquio foi uma oportunidade privilegiada de interação e discussão entre pesquisadores, além 
de ter dado oportunidade a um público ouvinte (assistentes sociais: docentes, pós-graduandos, supervisores de estágio, preceptores do PET-Saúde, participantes de Grupos de Pesquisa; estudantes de graduação: inseridos em grupos de pesquisa e Programas de Educação Tutorial, estagiários de Serviço Social) de conhecer os estudos que estão sendo realizados acerca da temática. $\mathrm{O}$ evento já está incorporado à programação da área de Serviço Social e sua próxima edição está prevista para 2015 na UFAL, em Maceió (AL).

Recebido em 9/8/2013

Aprovado em 14/8/2013 